\title{
LUPA Y LUPANAR EN LA NARRATIVA DE MARIO VARGAS LLOSA. SU MAGISTERIO EN LA OBRA DE SANTIAGO GAMBOA
}

\author{
Catalina Quesada Gómez \\ Universidad de Sevilla
}

\begin{abstract}
In ¿Quién mató a Palomino Molero? (1986), Vargas Llosa has recourse to some of the characteristic techniques of the noir fiction. In that novel, Vargas Llosa explores Piura's and Talara's underworld, recreates the oppressive atmosphere of Odría's Peru, shows Peruvian society's racism, exposes the ordinary people's lack of confidence in the police and finally, as he did in his previous novels, he attacks the army. By using some methods which are definitely against the police, nevertheless, he subverts the genre precepts, without reaching a parodic level. The presence of the brothel -a recurrent element in his fiction- has an effect on the development of the police investigation. The information the investigators get in the brothel is essential to resolve the case, being a novel which dispenses with the logical deduction process so characteristic of the classical detective novel. In Perder es cuestión de método (1997), Santiago Gamboa, the Colombian novelist, uses some of Vargas Llosa's imagery, in which the figure of the impaled person and the recurrence of brothel-related environments are constant sources of information.
\end{abstract}

El interés de Mario Vargas Llosa por el género policíaco ${ }^{1}$ se concreta en novelas como La ciudad y los perros (1963), ¿Quién mató a Palomino Molero? (1986) o Lituma en los andes (1993). Pero a pesar de la presencia de la intriga y de una pesquisa policial en La ciudad y los perros, el autor no se decide a escribir una novela que acepta algunas de las convenciones del género hasta ¿Quién mató a Palomino Molero?, novela cuyo estudio proponemos aquí.

Conviene, en primer lugar, delimitar de forma breve qué se entiende por novela policíaca, pues la crítica ha utilizado indistintamente términos como novela policíaca o policiaca, novela detectivesca, novela negra o género negro para designar un subgénero narrativo muy concreto. Es necesario deslindar qué abarca cada uno de esos marbetes. Por lo general, se acepta unánimemente la distinción más o menos clara entre la novela enigma, novela-problema o de cuarto cerrado y la novela de acción y suspenso. La novela enigma -a la que algunos llaman, sin más, novela policíaca-comprendería los textos clásicos del género, los de Edgar Allan Poe, Agatha Christie, o Arthur Conan Doyle, "en los que casi invariablemente la trama consiste en descubrir a un criminal que se esfuma en el espacio"2.

\footnotetext{
${ }^{1}$ El DRAE, en su edición de 2001, acepta ambos términos, policíaco y policiaco, si bien se prefiere la forma con tilde a la que no la lleva. Siguiendo los preceptos de la R.A.E., emplearé las formas policíaco y policíaca; sin embargo, respetaré la grafía sin tilde utilizada por algunos críticos cuando reproduzca un texto suyo.

${ }^{2}$ M. Giardinelli, El género negro. Ensayos sobre literatura policial, México D. F., Universidad Autónoma Metropolitana, 1996, p. 15.
} 
En cambio, la novela de acción y suspenso o novela negra, un producto del siglo XX, vendría caracterizada "por la dureza del texto y de los personajes, así como por la brutalidad y el descarnado realismo" (Giardinelli: 15). Los límites entre una y otra rama no siempre son tan nítidos como los críticos y taxónomos desearían, pero lo cierto es que tal separación resulta muy pertinente:

Histórica y sistemáticamente existe, sin lugar a dudas, una cercanía del término novela policíaca al subgénero novela detectivesca o de enigma y una cercanía del término novela negra al subgénero thriller. El primero conlleva la connotación de asesinato limpio, de investigación lógico-racional y de un comportamiento bien educado de los personajes; el segundo, la de violencia innecesaria, de un ambiente sórdido y de ciudades caóticas ${ }^{3}$.

Según esta definición, que se hace eco de lo sostenido por la mayor parte de los estudiosos del género, las obras de Mario Vargas Llosa de tinte policial estarían más en consonancia con la segunda vertiente - la de la novela negra- que con la de la novela policíaca clásica. Es éste un dato relevante que habremos de considerar en el análisis de ¿Quién mató a Palomino Molero?

Una segunda consideración pertinente es la de la situación de aquellos escritores que, sin ser realmente "autores de género", adoptan el formato de la novela negra o se valen de algunos de sus recursos. Planteaba Todorov en "Typologie du roman policier" que el escritor que se salía de los moldes precisos y definidos del género policial no construía una novela policíaca, sino auténtica literatura ${ }^{4}$. Al contrario de lo que sucede en los demás géneros, la mejor obra es la que no se aleja en nada de lo prescrito:

Le roman policier a ses normes ; faire «mieux » qu'elles ne le demandent, c'est en même temps faire moins bien: qui veut «embellir» le roman policier, fait de la «littérature», non du roman policier. Le roman policier par excellence n'est pas celui qui transgresse les règles du genre, mais celui qui s'y conforme [...] le meilleur roman sera celui dont on n'a rien à dire ${ }^{5}$.

Colmeiro rechaza esta división tajante de Todorov y considera que la argumentación según la cual una obra "popular" no puede transgredir las normas genéricas si no es dejando de ser popular se cae por sí misma. Establece que la pertenencia a la literatura o a la literatura popular no es de un género en bloque, sino de las obras concretas: "serán las obras individuales que manifiestan características de un género, en todo caso las que se deban someter a escrutinio"6. Además, el ejemplo de la novela policíaca es el menos indicado para un razonamiento como ése:

El caso de la novela policiaca tradicional parece contradecir especialmente la teoría de Todorov, pues una de sus convenciones comúnmente aceptadas es precisamente la creación

\footnotetext{
${ }^{3}$ H. Pöppel, La novela policíaca en Colombia, Medellín, Editorial Universidad de Antioquia, 2001, p. 4.

${ }^{4}$ Los prejuicios de la crítica contra este tipo de "literatura de masas" o "subliteratura" han sido y siguen siendo muy frecuentes, hasta el punto de que ha llegado a convertirse en tópico para casi todos los estudiosos del género aludir a ese desprecio de la intelectualidad por lo policíaco, tanto en su vertiente clásica como en la negra.

${ }^{5}$ T. Todorov, “Typologie du roman policier", Poétique de la prose, Paris, Éditions du Seuil, 1978, pp. 55-65; la cita corresponde a la p. 56.

${ }^{6}$ J. F. Colmeiro, La novela policiaca española: teoría e historia crítica, Barcelona, Anthropos, 1994, p. 43.
} 
constante de nuevas formas, infringiendo las anteriores. Todos los decálogos y normativas que han intentado prescribir las reglas a las que se debe ajustar una novela policiaca (mayormente prohibiciones), como las célebres de S. S. Van Dine, han sido sistemáticamente ignorados y transgredidos. El concepto esencial de fairplay, de juego limpio del autor con el lector, quizás el más defendido por los puristas del género tradicional, es prácticamente imposible de encontrar incluso entre aquellos autores que más confiesan su devoción por él [...]. La razón de ello está en la necesidad central del género de causar sorpresa, de explorar nuevas posibilidades, de mantener en vilo al lector engañándole, en un continuo "más difícil todavía" (Colmeiro: 43-44).

El problema que planteamos aquí es el de la consideración de escritores como Borges, Vargas Llosa, Muñoz Molina o Santiago Gamboa que han incursionado de forma esporádica en el género. Según Salvador Vázquez de Parga este tipo de obras, aun siendo "de género", estaría hecho "desde la literatura", con unos niveles de calidad que no se le presuponen a la denominada "literatura popular":

Debe considerarse al género policiaco como algo abierto a innumerables posibilidades, sin un sometimiento rígido a esas reglas capaz de impedir el desarrollo evolutivo de aquél. Esto significa en definitiva que también puede hacerse novela policiaca -como novela de aventuras, de espionaje, histórica, etc.- "desde la literatura", valiéndose para ello de elementos genéricos convenientemente asumidos e instrumentalizados, lo que sin duda no desnaturaliza el carácter policial de la narración, aunque lógicamente el resultado habrá de ser distinto del conseguido por la novela policiaca escrita "desde el propio género"7

En palabras de José F. Colmeiro, se trataría de un "uso 'culto' de fórmulas policiacas por parte de autores establecidos en el canon literario" (Colmeiro: 35). Y cita a Borges y a su "novela policiaca metafísica" ("La muerte y la brújula", "El jardín de senderos que se bifurcan"); a Robbe-Grillet, Graham Greene, Dürrenmatt, Gadda, Sciascia, Eco, Eduardo Mendoza y a Manuel Vázquez Montalbán. Todos ellos arrastrarían la novela policíaca o negra, según el caso, al marco general de la literatura, la literatura con mayúscula, aunque no siempre se vea de forma nítida cuándo hay que ponerla.

Quizá por el desprestigio del género policial, quizá por el peso de sus magnas novelas, la crítica no vio con buenos ojos esta novelita que no llegaba a las doscientas páginas. Críticas acerbas, como la de Julio Ortega, denunciaban la falta de calidad de ¿Quién mató a Palomino Molero?:

Mario Vargas Llosa parece haber perdido en esta novela su identidad creadora. Es una novela que falla incluso dentro de los límites, bastante reducidos por sus últimos libros, de un proyecto narrativo que ha ido perdiendo inteligencia y pasión. Retóricamente, cabe esta pregunta: ¿Quién mató a Vargas Llosa, el inconformista apasionado de los primeros libros? Y menos retóricamente se podría responder: Tú, hipócrita lector, novelero y complaciente ${ }^{8}$.

Otros críticos, con posterioridad, se han encargado de rescatar la novela de la pira inclemente y de reconocer la valía de la obra, en especial por la "reunión globalizadora [...]

\footnotetext{
${ }^{7}$ S. Vázquez de Parga, La novela policiaca en España, Barcelona, Ronsel, 1993, p. 12.

${ }^{8}$ J. Ortega, "García Márquez y Vargas Llosa, imitados", en Revista Iberoamericana, LII, 137 (1986), pp. 971-979; la cita corresponde a la p. 979.
} 
de inquietudes y obsesiones típicamente vargallosianas"9. En esa misma línea, Armas Marcelo, en su biografía de Vargas Llosa, enumera los vínculos de esta novela corta -que el autor habría desgajado de La casa verde-con otras obras anteriores:

¿Es una novela de intriga, un relato policíaco, un juego de espejos con fórmulas tradicionales de suspense gobernando las páginas de esta novela corta? ¿Quién mató a Palomino Molero? goza de parentesco con La ciudad y los perros -la institución militar es, de nuevo, puesta en duda en su integridad moral y en su apariencia marcial-, con ese Perú "jodido" de Conversación en La Catedral, y con algunos episodios y escenarios vagamente parecidos a algunos de La casa verde, de donde además salen también las sombras de algún personaje que empieza a ser constante en la novelística de MVLL, como un ser errante que aparece y desaparece de las páginas de su novela: Lituma ${ }^{10}$.

Sin entrar en este tipo de cuestiones, analizaremos ¿Quién mató a Palomino Molero? desde el punto de vista genérico, deteniéndonos en la presencia del prostíbulo -motivo recurrente en la narrativa de Vargas Llosa-y en su función en la trama policial.

\section{1. ¿QuiÉn Mató a Palomino Molero?, NOVEla neGRa.}

Establier Pérez subraya la adscripción de ¿Quién mató a Palomino Molero? a la "línea del género policiaco más tradicional" (137) y enumera los rasgos que, en efecto, relacionan la novela con dicho género. Sin embargo, es preciso matizar tal afirmación porque, en primer lugar, no es ésta "una novela policiaca con todos los ingredientes tradicionales del género" (Establier Pérez: 136-137); y, en segundo lugar, la proximidad se da con respecto a la novela negra de forma mucho más clara de lo que lo hace con la novela policíaca clásica.

La filiación con el género negro se produce por la existencia de un ambiente nocturno caracterizado por una cierta degradación, que remite al descrito en La casa verde (1966); aquí los detectives, recurren a técnicas duras -propias del hard boiled norteamericano- ${ }^{11}$ para obtener informaciones que permitan que la investigación avance. La lógica por la que se rige la novela policial clásica no tiene cabida en ¿Quién mató a Palomino Molero?, si bien la pregunta que se le plantea al lector desde el título es la misma que vertebra la estructura de ésta, el clásico whodunit. De hecho, como muy bien ha visto Hernández de López, "lo policíaco en esta novela empieza con el título, puesto que la trama de la misma [...] no constituye una gran intriga. Son raros los momentos en que el lector se siente atrapado por el enredo; pero el título sugiere al menos un devaneo policial"12.

Pero al contrario de lo que sucede en la novela negra, donde la ciudad moderna es el escenario en el que se desarrollan los hechos, el ambiente de ¿Quién mató a Palomino

\footnotetext{
${ }^{9}$ H. Establier Pérez, Mario Vargas Llosa y el nuevo arte de hacer novelas, Alicante, Universidad de Alicante, 1998, p. 152.

${ }^{10}$ J. J. Armas Marcelo, Vargas Llosa. El vicio de escribir, Madrid, Alfaguara, 2002, p. 345.

${ }^{11}$ Se denomina hard boiled novels a las obras de género negro que aparecen en Estados Unidos en la década de 1920, tales como las de Dashiell Hammett y, con posterioridad, las de Raymond Chandler, y que se caracterizan por la dureza de sus detectives y sus métodos, así como por un estilo que podría ser calificado de "realismo sucio". ${ }^{12}$ A. M. Hernández de López, "Que el racismo mató a Palomino Molero no es la verdad de las mentiras", en Mario Vargas Llosa: opera omnia, Madrid, Pliegos, 1994, pp. 125-132; la cita corresponde a la p. 128.
} 
Molero? es rural ${ }^{13}$. Esta circunstancia no impide que el narrador conduzca a los personajes por bares y tugurios, por los bajos fondos piuranos. Así, el Teniente Silva y Lituma empiezan a recoger datos que los aproximen a la resolución del caso gracias al Teniente Dufó, al que encuentran armando escándalo en el bulín del Chino Liau. Resulta interesante la ambientación no urbana de ¿Quién mató a Palomino Molero?, así como la andina de Lituma en los Andes, por cuanto supone una vuelta a los orígenes del género, tal y como lo ha entendido Mempo Giardinelli. Para el crítico y escritor argentino, tanto ambientes como temas, personajes o estilos sirven para establecer una clara relación entre el western y el género negro. De la ambientación, que es lo que ahora nos ocupa, dice que el espacio salvaje e inhóspito de la literatura del Far West encuentra su continuidad en el ambiente de la ciudad moderna, igualmente desapacible y feroz (Giardinelli: 29). Si la ciudad había sido el escenario clave de novelas como La ciudad y los perros o Conversación en La Catedral, será el mundo selvático o andino -agreste, de cualquier modo- el entorno para otras muchas de sus obras ${ }^{14}$.

Vargas Llosa modifica el tratamiento de la corrupción policial en la novela, que en este caso es más imaginada que real. Ni el Teniente Silva ni Lituma son los típicos personajes que aceptan sobornos, corruptos irremediables, que encontramos en las novelas de género ${ }^{15}$. Sin embargo, el escepticismo de las gentes ante la versión policial, o las iniciales acusaciones de que hubiera habido pagos que fomentaran la irresolución del caso, apuntan a una sociedad acostumbrada a las corruptelas. Curiosamente, la historia real que conoce el lector -nada indica que sea falaz, aunque bien pudiera serlo- no resulta en absoluto convincente para el resto de los personajes: "Amigo Lituma, por qué no nos dice cuánto le pagaron al Teniente los peces gordos para inventar la historia ésa del suicidio del Coronel" (187). El mismo Lituma resume al final de la novela cuáles son las elucubraciones de la gente: "Lo cojonudo de todo esto es que nadie se cree que el Coronel Mindreau mató a la muchacha y luego se mató -dijo-. Hablan las cojudeces más grandes, mi Teniente. Que fue un crimen por el contrabando, que por espionaje, que metió la mano el Ecuador. Y hasta que fue por cosas de rosquetes" (188).

Esta desconfianza en la policía es una constante desde los orígenes del género; en la novela policial clásica el detective se adelanta siempre a la policía, cuya incapacidad suele quedar destacada ${ }^{16}$; y algo parecido acontece en las novelas del hard boiled norteamericano.

\footnotetext{
${ }^{13}$ Coincide Vargas Llosa en la preferencia por el espacio no urbano con el mexicano Jorge Ibargüengoitia, que tanto en Las muertas (1977) como en Dos crimenes (1979) subvierte una de las convenciones del género negro, situando la acción en el mundo rural.

${ }^{14}$ Como veremos en la segunda parte de este estudio, lo que realmente le ha interesado a Santiago Gamboa de Vargas Llosa ha sido su condición de narrador urbano. De ahí que, pese a la influencia evidente de ¿Quién mató a Palomino Molero? en la gestación de Perder es cuestión de método, el colombiano haya preferido la ciudad moderna como escenario para su novela.

${ }^{15}$ Aunque los personajes no se degradan de esa forma, tampoco podemos afirmar que sean guardias ejemplares, desde el momento en que sus amoríos priman sobre la investigación. Cuando Silva y Lituma espían a Adriana mientras se baña, se convierten en objeto de los insultos de Alicia: "Son todavía peor de lo que dice la gente que son los policías”, M. Vargas Llosa, ¿Quién mató a Palomino Molero?, Barcelona, Seix Barral, 1986, p. 114. En adelante cito en el texto, indicando la página entre paréntesis.
}

${ }^{16}$ Nótese que tanto en ¿Quién mató a Palomino Molero? como en Lituma en los Andes los investigadores no están al margen del cuerpo, sino que son miembros de la Guardia Civil peruana. 
Pero en la literatura hispanoamericana, a esa ineptitud manifiesta se añade la sospecha de la corrupción, el odio arraigado en el sentir de las gentes, algo que la aleja de la confianza en la ley propia de la sociedad norteamericana:

La no admiración, la no aceptación del poder policial [...] es natural en América Latina. [...] En América Latina no sólo hay poca confianza en la policía, sino que hay odio y rencor. Un policía es custodia de un orden; tiene una misión conservadora por esencia: a través de la defensa de la propiedad [...] se trata de impedir mutaciones que no estén normadas jurídicamente. El rol policial, pues, es el de conservar un determinado statu quo. Esto no está mal per se. Pero lo que sucede es que evidentemente en América Latina, casi desde siempre, el orden a conservar por los poderes policiales es un orden injusto: el orden de las oligarquías. (Giardinelli: 245-246)

A la luz de estas circunstancias, cobran relieve las acusaciones hacia el Teniente de ocultamiento de información, "porque los asesinos son peces gordos" (31-32). Pero se trata de falsas imputaciones, según lo que conoce el lector, y el narrador, desde el punto de vista de Lituma, se encarga de afirmar lo contrario:

Cierto, el Teniente era hombre recto y, por eso, Lituma le tenía, además de aprecio, admiración. Era bocón, lisuriento, algo chupado, y, cuando se trataba de la gorda cantinera, perdía la chaveta, pero Lituma, en todo el tiempo que llevaba trabajando a sus órdenes, lo había visto esforzarse siempre, en todas las denuncias y querellas que llegaban a la Comisaría, por hacer justicia. Y sin preferencia por nadie (32).

De todos modos, la crítica social que suele acompañar a toda novela negra no está ausente en la obra que ahora estudiamos; el ambiente opresivo del Perú de Odría, sin que en ningún momento se explicite, está como telón de fondo y tiene su correlato, en lo formal, en la configuración de la novela, tal y como lo ha destacado Ryan-Ranson:

Para hacer su condena de la corrupción y los falsos valores sociales en el Perú, Vargas Llosa combina la realidad y la fantasía para crear un ambiente novelístico alucinante, enajenado, angustioso, tenso e irreal que capta la esencia del mundo grotesco engendrado cuando un país es dominado por las fuerzas satánicas de un tiránico sistema político que es totalmente indiferente al triunfo de la justicia y la revelación de la verdad ${ }^{17}$.

Indicadores diversos revelan el ambiente claustrofóbico y opresivo del Perú de los años 50 (Ryan-Ranson: 142-143). Entre ellos, cabe destacar las continuas referencias al mal olor dispersas a lo largo de la novela, desde el que desprende el cuerpo putrefacto de Palomino Molero (7), hasta el fuerte e insoportable olor del pescado (75), pasando por las alusiones al olfato de los investigadores ("algo me huele raro. ¿A ti no?”, 53; "hoy descubriremos algo, se huele en el aire", 74).

Otras de las características propias del género, relacionadas también con la crítica social, tienen cabida en ¿Quién mató a Palomino Molero? Según Giardinelli,

los problemas de conciencia, el fanatismo religioso y aun el racial [...] también están presentes en los autores de América Latina, pero adaptados a nuestra propia tragedia, que es más bien

\footnotetext{
${ }^{17}$ H. L. Ryan-Ranson, “Lo grotesco en ¿Quién mató a Palomino Molero?”, en Hernández de López 1994: 139150; la cita corresponde a las pp. 139-140.
} 
griega que shakesperiana, digamos. Casi no hay novela policial latinoamericana que no aborde, aunque sea tangencialmente, nuestras formas de racismo, los dogmas (no tanto religiosos, pero sí políticos e ideológicos) y sobre todo las formas de violencia social que nos son propias (Giardinelli: 239).

Para Hernández de López, el problema del racismo constituiría la última verdad de la ficción (131), en un país como el Perú, donde existe tal pluralidad racial. La única razón por la que el Coronel Mindreau no tolera las relaciones entre su hija y Palomino es porque se trata de un cholo; frente a él prefiere al teniente Dufó, borracho y pendenciero, pero blanquito. Además, son muchos los comentarios que hace Lituma en relación con su condición de cholo y con el rechazo que eso provoca en determinadas personas.

Estas consideraciones pueden servirnos para desmentir que, frente al interés político o social de otras novelas anteriores, no lo haya en ¿Quién mató a Palomino Molero? En palabras de su biógrafo, la novela debe ser insertada "entre las máximas preocupaciones del escritor MVLL, las que manejan sus narraciones entre Historia de Mayta (1984) y El hablador (1987). Son preocupaciones cuyo poso último es una constante de filosofía política" (Armas Marcelo: 346).

Y algo parecido se puede decir del cuidado en la forma. Si la mayoría de novelas calificadas "de género" se caracteriza por la ausencia de cualquier pretensión formal, no sucede tal cosa en ¿Quién mató a Palomino Molero? Vargas Llosa sigue empleando algunas de las técnicas narrativas que lo han acompañado durante su carrera de escritor: la de los vasos comunicantes o técnica del contrapunto ${ }^{18}$, que le permite relacionar la historia de Palomino Molero y Alicia Mindreau con la del Teniente Silva y Adriana. Y a la vez, utiliza recursos que apuntan a la "elaboración artística de la novela", tales como su estructura circular, la manipulación del tiempo y del espacio, la creación de arquetipos, el distanciamiento irónico o la utilización de elementos que revelan lo grotesco en el texto (Ryan-Ranson: 140). El contrapunto se manifiesta de distintos modos en la novela; uno de los ejemplos más evidentes es el del paralelismo entre la historia principal y la secundaria, la de los amores del Teniente Silva por Doña Adriana: a la tragedia de la acción primera se le termina contraponiendo el final burlesco de la secundaria. Mediante dicha técnica, tan propia del discurso narrativo vargallosiano, el autor incorpora y personaliza una de las constantes del género: la presencia de interludios amorosos como "condimento narrativo indispensable" (Giardinelli: 33-34).

Desmentido que no haya en ¿Quién mató a Palomino Molero? preocupaciones de índole político-social y formal, queda ahora un tercer desmentido. Con frecuencia se ha afirmado que la novela negra o policial es literatura (o paraliteratura) de evasión, una lectura fácil para lectores poco exigentes que no desean ser molestados en exceso con complicaciones ideológicas. Pero en esta novela Vargas Llosa plantea, entre líneas, una cuestión a mitad de camino entre lo literario y lo filosófico, como es la de lo problemático del acercamiento a la verdad. ¿Cuál es la realidad de la novela? Al lector le queda la duda de que la versión que posee sea la "real": ¿eran ciertos los abusos de Mindreau o se trataba de una invención de la hija?; ¿por qué se muestra tan escéptica la gente con la explicación

18 K. M. Taggart, "La técnica del contrapunto en ¿Quién mató a Palomino Molero?”, en Hernández de López 1994, pp. 151-158. 
de Silva y Lituma? E incluso nos asaltan dudas acerca de la veracidad de la historia contada por Doña Adriana después de conocer lo que le dice Lituma:

-Nadie se cree la historia del suicidio del Coronel Mindreau -cambió de tema, de pronto, Doña Adriana.

-Así estoy viendo -murmuró Lituma.

-La verdad es que yo tampoco -añadió la dueña de la fonda-. En fin, cómo será.

- ¿Usted tampoco se la cree? -Lituma se puso de pie y firmó el vale por el almuerzo-. Sin embargo, yo sí me creo la historia que usted me ha contado. Y eso que es más fantástica que el suicidio del Coronel Mindreau (186-187).

Inmediatamente nos preguntamos por qué utiliza Lituma el adjetivo fantástica, cuando sería más lógico que hablase de verosimilitud: términos como increíble o inverosímil no resultarían tan chocantes como fantástica". Para Taggart, lo que sucede es que "la convergencia de los dos hilos narrativos produce una realidad en la cual lo real y lo fantástico se funden. La versión que los talareños inventan sobre lo de Palomino Molero es más real para ellos que lo que realmente pasó" (Taggart: 157). De hecho, poco antes la historia narrada por Doña Adriana se iba entremezclando con los comentarios de incredulidad por la historia de Molero y Mindreau y con las nuevas versiones de lo sucedido por parte de los presentes en el bar.

\section{Procedimitentos ANTIipoliciales.}

Decíamos que no era posible afirmar, como lo hace Establier Pérez, que sea ésta "una novela policiaca con todos los ingredientes tradicionales del género". Desde el momento en que el narrador introduce procedimientos "antipoliciales", que implican una inversión del modelo, nos adentramos ya en el terreno de la parodia ${ }^{20}$. En ¿Quién mató a Palomino Molero? el final resulta completamente irónico; no tanto porque los culpables queden impunes -Mindreau se suicida y a Dufó se le presupone alguna condena- ${ }^{21}$ como por el castigo que reciben los investigadores en pago de la resolución del caso, acerca de lo cual ellos mismos reflexionan:

-Ya ves, pedazo de huevón -lo amonestó su jefe con cierto afecto-. Tanto que querías aclarar el misterio de Palomino Molero. Ya está, te lo aclaré. Y qué ganamos. Que te manden a la sierra, lejos de tu calorcito y de tu gente. Y a mí tal vez a un hueco peor. Así se agradecen los buenos trabajos en esta Guardia Civil a la que tuviste la cojudez de meterte. Qué va a ser

\footnotetext{
${ }^{19}$ Poco después será el adjetivo increíble el utilizado para describir la historia: "Increíble lo que le había contado Doña Adriana. ¿Sería cierto? Sí, debía ser” (188).

${ }^{20}$ Stefano Tani ha enumerado algunos de estos procedimientos antipoliciales. Así, serían procedimientos paródicos que la solución sea encontrada por azar, que el desenlace no implique castigo para los culpables, que no haya solución o que el final sea burlón o inverosímil; S. Tani, The Doomed Detective: The Contribution of the Detective Novel to Postmodern American and Italian Fiction, Carbondale, Southern Illinois Up, 1984, p. 43. No he tenido acceso a esta obra; cito por E. Sklodowska, La parodia en la nueva novela hispanoamericana (1960-1985), Amsterdam / Philadelphia, John Benjamins Publishing Company, 1991, p. 122.

${ }^{21}$ No está claro del todo que Dufó vaya a recibir condena. Silva anuncia que será juzgado por el fuero privativo, pero, conociendo las reticencias vargallosianas contra el estamento militar, las suposiciones de Silva pueden ser interpretadas como auténticas dudas del personaje: "Se supone que no se puede ir tan tranquilo a su casa [...] Algo le harán, supongo" (174).
} 
de ti allá, Lituma, dónde se ha visto gallinazo en puna. Me muero de pena sólo de pensar en el frío que vas a sentir (189).

Subyace en la novela una crítica implícita - a veces explícita- al ejército; sin embargo, a diferencia de lo que sucedía en La ciudad y los perros, el ejército no logra silenciar la verdad: Silva y Lituma sondean el fango de la vida militar y sacan a la luz lo que Mindreau se empeñaba en ocultar. Para Establier Pérez este cambio con respecto a su primera novela podría suponer "un atisbo de esperanza en el futuro frente a ese nihilismo atroz del que había hecho gala anteriormente" (143), pero el traslado apuntaría a la insuficiencia de los cambios en el sistema: "queda en cuestionamiento permanente la institución militar, obstinada siempre en atajar cualquier brote de efectividad y eficiencia en su seno susceptible de poner de manifiesto los entresijos de esa capa superficial de honorabilidad y pundonor" (Establier Pérez: 144).

A la vez, el desenlace humillante para Silva de la historia amorosa con Doña Adriana redunda en el tono generalizado de fracaso y burla que se desprende de la obra. Igualmente antipolicial y paródico resulta el desarrollo de la investigación. Los guardias son conscientes de que dan palos de ciego, y de que sólo de ese modo encontrarán la solución: "como en este asunto no damos pie con bola, hay que pegar manotazos a todos lados a ver si achuntamos aunque sea de casualidad" (54). En este sentido, hay que atribuir al prostíbulo un papel destacado en lo que respecta a la introducción del azar en el desenlace; los guardias se dirigen allí porque, como enclave donde se da cita la peor fauna de la localidad, siempre será posible averiguar algo, "si no, por lo menos habrá sido un pretexto para echar una ojeada al bulín y pasar revista al material" (54).

Con respecto a la motivación que guía la investigación, también existe un cierto alejamiento de la ortodoxia genérica. Se supone que el detective, una persona íntegra, debe perseguir el restablecimiento del orden social, momentáneamente alterado por los malhechores. Para Lituma el caso se convierte en una obsesión, con la imagen del flaquito siempre en mente, al que imagina en todas partes; incluso él mismo descarta el legítimo deseo de que se haga justicia como estímulo para resolver el caso: "Más que una necesidad de justicia o de venganza, sentía una curiosidad ávida por ver sus caras, por escuchar los motivos que habían tenido para hacer lo que habían hecho con Palomino Molero" (33). Y sus compadres apuntan a fines aún menos altruistas: "Resuélvelo y te ascenderán a general, Lituma" (9), afirmación ésta que torna aún más irónico el destierro final a Junín.

Un último rasgo desestabilizador lo constituye el hecho de que la gente no crea la versión real: aunque la justicia ha actuado, nadie cree en el suicidio del Coronel, con lo cual, tampoco los investigadores reciben el reconocimiento público.

\section{Prostíbulos, Lupanares, Burdeles.}

El crítico colombiano Luis H. Aristazábal, acaso un tanto alejado de los derroteros por los que transita la nueva narrativa hispanoamericana, ${ }^{22}$ ha censurado en la obra Fulanitos de tal, zulanitas de tul (1996), de Luis Aguilera, la aparición de los más bajos y rastreros fondos; pecado éste que también cometería Vargas Llosa:

\footnotetext{
${ }^{22}$ Quizá hubiera que eliminar todos los adjetivos y decir, sin más, los derroteros de la narrativa, o incluso de la literatura y del arte. No sabemos qué pensará el citado crítico del arte barroco -por no remontarnos a la Antigüedad Clásica-, o del naturalista, tantas veces plagados de sordideces y mezquindades.
} 


\begin{abstract}
Es el mismo problema que veo en Vargas Llosa, un deslinde irreconciliable entre un lenguaje fino y una materia sórdida. Quien cree que historiar realidades mezquinas es bella cosa, que se puede escribir bien y ser aburrido, no produce más que un engendro informe que termina en prosa prosaica, prosa de garito y de burdel. Y simplemente se deja de paladear esas páginas, porque aunque hay mucha gente que escribe bien, hay pocos que aciertan a escribir bien sobre temas "bien". Tengo para mí que escritores tan agradables como Mario Vargas Llosa fracasan esencialmente por regodearse entre lo sórdido y mezquino, habiendo temas más dignos de tan buena pluma. El mismo Macondo, mirado desde un punto de vista realista, no pasaría de ser una aldea maloliente, malsana y miserable, perdida en medio del Magdalena. Pero García Márquez ve todo lo que no es mezquindad y sordidez en ella y nos lo hace ver, todo lo contrario de lo que sucede en novelas como La ciudad y los perros. Y es que no se puede novelar lo innovelable, los intersticios, las idas al baño, las conversaciones anodinas ${ }^{23}$.
\end{abstract}

La predilección de Vargas Llosa por novelar este tipo de espacios prostibularios lo ha llevado incluso a titular una de sus novelas con nombre de burdel. Pero no nos detendremos aquí en el análisis de un asunto como éste, sobre el que se podría escribir abundantemente. Nos interesa ahora la función de estos lugares en el desarrollo de la trama policial y tan sólo atenderemos a esas otras casas de lenocinio que adornan su novelística cuando existan vínculos evidentes entre unas y otras.

Haciéndonos eco de la línea que Giardinelli establece entre el western y la novela negra, es posible identificar la cantina o taberna de la literatura del Far West con los bares y casas de juego y/o mal vivir que abundan en las novelas del género negro. No siempre se trata de prostíbulos; a veces son night-clubs donde los personajes asisten a espectáculos de baile o streep-tease protagonizados, casi siempre, por mujeres ${ }^{24}$. A diferencia de lo que sucede en la versión clásica del género, donde el detective recurre a la lógica para hilvanar las pistas, en este tipo de obras es el sondeo de los estratos más bajos de la sociedad el mayor proveedor de pistas. Pero recordemos que incluso Sherlock Holmes acudía a los fumaderos de opio para tener noticia de aquello que resultaba inalcanzable mediante la lógica.

El prostíbulo itinerante descrito al principio de la novela incorpora parcialmente la movilidad de que han hecho gala otros, como el del urugayo Enrique Amorín, que en La carreta (1929-1952) nos muestra un burdel ambulante; o la carpa del amor que García Márquez construye en "La increíble y triste historia de la cándida Eréndira y de su abuela desalmada", un año antes de la publicación de Pantaleón y las visitadoras (1973), donde el mismo Vargas Llosa habla de lupanares motorizados o casas de citas transeúntes. En ¿Quién mató a Palomino Molero?, como en La casa verde, la presencia de un representante de la iglesia obliga al cierre del bulín, que no tarda en renacer de sus cenizas:

El bulín del Chino Liau había deambulado por medio Talara, perseguido por el párroco. El padre Domingo, apenas lo detectaba, lo hacía clausurar por la Alcaldía. Pocos días después de la clausura, el bulín volvía a resucitar en una cabaña o casita, tres o cuatro manzanas más allá.

\footnotetext{
${ }^{23}$ L. H. Aristazábal, "La generación de la diáspora contraataca", en Boletín Cultural y Bibliográfico, 45, XXXIV (1997). Biblioteca Virtual Banco de la República. Internet. 19/05/04. <http://www.banrep.gov.co/blaavirtual/ boleti1/bol45/resen.htm>

${ }^{24}$ En este sentido, cabe considerar a la novela negra heredera directa del culto a la hombría de la novela del oeste. Con frecuencia, las obras de D. Hammett y R. Chandler han sido declaradas abiertamente machistas, cuando no misóginas. Estos valores son fácilmente trasladables a las sociedades hispanoamericanas, máxime en una novela como ¿Quién mató a Palomino Molero?, que se desarrolla en el Perú de los años 50.
} 
El Chino Liau ganó, al fin. Ahora estaba a la salida del pueblo, en un almacén de tablones acondicionado de cualquier manera. Era primitivo y endeble, con su suelo de tierra regado a diario para que no hubiese polvo y un techo de calaminas sueltas, que chirriaban con el viento. Los cuartitos de las polillas, al fondo del local, estaban llenos de rendijas por donde los churres y los borrachos venían a espiar a las parejas (53-54).

Este local tiene más de cantina de novela del oeste, de salón de fiestas, que de los modernos bares citadinos, pero sus rasgos vienen motivados por la localización rural de la novela ${ }^{25}$. Lo relevante del sitio es que ahí se produce el encuentro con Dufó, que pone a Silva y a Lituma sobre la pista correcta. El reclamo para acudir al bulín lo constituye una de las prostitutas, la Loba Marina, que acude a quejarse a Silva por los excesos del tenientito; las quejas sucesivas que recibe lo deciden a personarse en el lugar y averiguar a qué se debe tal actitud: "Nadie va a matonear así en el bulín, donde están los tipos más peligrosos de Talara, sólo por hacerse el gracioso. Y cuatro días seguidos. Algo me huele raro" (53). En el prostíbulo descubren que el tenientito y el enamorado de Alicia Mindreau son la misma persona y se deciden a interrogarlo cuando su embriaguez asegure respuestas sustanciosas.

\section{Santiago Gamboa ${ }^{26}$}

Cuarenta años después de que a Mario Vargas Llosa le concedieran el Premio Biblioteca Breve Seix Barral por La ciudad y los perros, Santiago Gamboa publica en esa misma editorial una novela que lleva por título uno de los que Vargas Llosa había descartado para su obra, Los impostores. La devoción de Gamboa por Vargas Llosa está más que atestiguada en todas sus obras, pero el autor también la ha explicitado cada vez que se le ha preguntado por su relación con la tradición literaria:

La obra de García Márquez ha sido un aprendizaje, porque demostró que se puede crear de la nada un interés por algo que durante muchos años fue desdeñado, mal visto. Yo me acerco con una admiración absoluta a esa creación literaria que me parece de primera categoría, pero no nutre una parte mía. Me siento más cercano a la obra de Vargas Llosa como escritor, él es un escritor de ciudad ${ }^{27}$.

La huella de Mario Vargas Llosa en la narrativa de Santiago Gamboa es amplia: desde alusiones directas en sus obras a las del peruano, hasta referencias mucho más sutiles y, a veces, difíciles de ver, pasando por la similitud en sus respectivas formas de concebir la literatura. Dado el tema de este trabajo, trataremos de esbozar las posibles relaciones de

\footnotetext{
${ }^{25}$ Resulta curioso, si no significativo, que los dos investigadores se dirijan al bulín precisamente "después de ver una película de vaqueros en el cine al aire libre" (54).

${ }^{26}$ Santiago Gamboa es un narrador colombiano (Bogotá, 1965), afincado en Europa desde 1985. Publicó su primera novela en 1995 (Páginas de vuelta, Bogotá, Norma; Barcelona, Mondadori, 1998), a la que siguieron las novelas Perder es cuestión de método (Barcelona, Mondadori, 1997), Vida feliz de un joven llamado Esteban (Barcelona, Ediciones B, 2000) y Los impostores (Barcelona, Seix Barral, 2002). También ha publicado un libro de viajes (Octubre en Pekín, Barcelona, Mondadori, 2001) y uno de relatos (El cerco de Bogotá, Barcelona, Ediciones B, 2003). Ha trabajado como periodista y actualmente colabora en la revista colombiana Cambio, donde tiene una columna semanal.

${ }^{27}$ Anónimo (nota de prensa), "Es muy atractivo armar desde lejos una patria imaginaria", entrevista para La Maga, 16 de diciembre de 1997. Internet. 12/05/03. <http://www.lamaga.com.ar/www/area2/pg_nota.asp?id_nota $=3643>$
} 
Perder es cuestión de método - una novela en la que el autor adopta en parte el molde del género negro- con lo visto de Mario Vargas Llosa.

La presencia de Vargas Llosa se deja ya sentir en la dedicatoria de Perder es cuestión de método: "A la memoria del fotógrafo Ricardo Gamboa, que disfrutó leyendo a Dickens y a Vargas Llosa, y a quien tanto quise. Con el legítimo deseo de regalarle este libro". Pero es al comenzar la novela cuando el lector se adentra en la imaginería vargallosiana con el hallazgo de un cadáver empalado a orillas del Sisga. Palomino, ahorcado y empalado, tiene su correlato en el ahogado y empalado desconocido del que no sabremos que es Ósler Estupiñán hasta el capítulo 9 de la segunda parte. Ambos, putrefactos y malolientes, son ridiculizados mediante comparaciones degradantes o burlescas: mientras que Moya compara al empalado con un Mercurio Galante ${ }^{28}$, de Palomino afirma el narrador que "más parecía un espantapájaros o un Ño Carnavalón despatarrado que un cadáver" (5). La investigación de Silanpa en Perder es cuestión de método se basa al principio en la identificación del cadáver, algo innecesario en la novela de Vargas Llosa; pero cuando Silanpa recurre a su amigo Guzmán para que lo oriente en sus indagaciones, éste le advierte lo siguiente:

-Hay que ver si ya se ha hecho algo parecido -analizó Guzmán-. Mirar en los archivos de la policía si alguien ha sido ya empalado, o crucificado, o ahorcado y dejado al aire libre. Hay que buscar apoyo en algo, la única pista no puede ser la identificación del cadáver ${ }^{29}$ (25).

También Lituma refiere la insuficiencia de haber identificado al cadáver de cara a la resolución del caso. La búsqueda en el archivo literario, en lugar del policial propuesto por Guzmán, nos conduce a Palomino Molero, sin que esto llegue a tener relación con el desenlace de la novela, ni nos aporte una información privilegiada más allá del mero goce estético de la intertextualidad.

Es posible atribuir la proliferación de bares y night-clubs en las obras de Gamboa a sus preferencias literarias: desde esos personajes de Graham Greene que "de modo invariable, dictaminan a las once de la mañana que es hora de tomarse un buen trago"30, hasta versiones mucho más latinoamericanizadas, sin olvidarnos de la novela negra norteamericana y sus bebedores de bourbon (los personajes de Dashiell Hammett o Raymond Chadler). Como sucede en ¿Quién mató a Palomino Molero?, las primeras informaciones sobre el caso son conseguidas en un night-club, el bar Lolita, un espacio decadente y sórdido donde Estupiñán y Silanpa sonsacan a Lotario Abuchijá. La descripción del narrador abunda en la oscuridad del local y en el olor nauseabundo:

El lugar olía a orines de gato. En la puerta había un sordomudo que, con gestos, lo invitó a subir por una estrecha escalera. Cuando Silanpa entró, el hombre se apretó los testículos queriendo decirle que arriba había buenas mujeres. La escalera lo llevó a un segundo piso.

\footnotetext{
${ }^{28}$ S. Gamboa, Perder es cuestión de método, Barcelona, Mondadori, 1997, p. 11. En adelante cito en el texto, indicando la página entre paréntesis.

${ }^{29}$ El carácter ritual del empalamiento, fuera de toda duda, tiene clara conexión con la crucifixión. Recuérdese la aparición de este último tipo de muerte en Pantaleón y las visitadoras a manos de la Hermandad del Arca. En Perder es cuestión de método al empalado también se lo compara con "un Cristo obeso" (12).

${ }^{30}$ S. Gamboa, El cerco de Bogotá, Barcelona, Ediciones B, 2003, p. 139.
} 
Luego a una puerta negra con un timbre. [...] Estaba muy oscuro. Había que acostumbrar la vista y Silanpa comenzó a buscar a Estupiñán. Avanzó hacia la barra y chocó contra una mesa mal iluminada en la que un hombre de corbata cabeceaba frente a una copa de aguardiente. En las demás mesas había mujeres dormidas y hombres que las manoseaban. De una rocola salía música ranchera. Al fondo, pasando un corredor, vio la sala de billar (39).

El prostíbulo, además de desempeñar un papel fundamental en la evolución de las investigaciones, contribuye al enrarecimiento del ambiente e incrementa el grado de decrepitud que rezuma la novela. En el relato "El cerco de Bogotá", la discoteca La Catedral -de indudables resonancias vargallosianas- cumple con la misma función estructural: ahí Bryndis obtiene la información necesaria del teniente Cote gracias al alcohol y a su cuerpo. El lugar, que tiene algo de infernal, resulta más repugnante incluso que el bar Lolita:

La discoteca era un local repleto de humo y paredes ennegrecidas, en el segundo sótano de un viejo edificio de Telecom, en la zona de Chapinero. Se llamaba La Catedral y era uno de los pocos lugares de diversión que no había cerrado después del cerco, pero en realidad le decían La Catedral de la Carne, pues a pesar de no ser claramente un burdel, en sus rincones oscuros se podía sorprender a parejas ocasionales practicando la fellatio, el cunnilingus $\mathrm{y}$, por supuesto, las múltiples penetraciones; otras cosas, como el sexo de grupo y, aunque mal visto, los tocamientos entre varones, se realizaban en corredores adyacentes en los que no había iluminación, y, a cambio, mucha humedad y roedores (Gamboa 2003: 37).

La Catedral se perfila como un perfecto espacio heterotópico, "un espacio real capaz de desarticular el todo del cual forma parte"31, en el que se invierten las normas sociales de una ciudad devastada: "La cercanía de la muerte había generado un ansia de libertinaje. Todo el mundo quería irse sosegado a la tumba" (Gamboa 2003: 37). Pero este seudoburdel es también un exponente de otros espacios reales, auténticos antros que son descritos con un realismo casi hiriente, y que no necesariamente son símbolos de toda una comunidad, sino más bien albergue de sus más bajos representantes. Y es aquí donde llega el "salpicón satírico", que remite nuevamente a Vargas Llosa, porque los periodistas Olaf K. Terribile y Bryndis Kiljan llegan al tugurio subterráneo por indicación de los militares:

Me hablaron de una discoteca clandestina en el barrio de Chapinero. Dicen que es la única que funciona en Bogotá, pues se escapa a las reglas de aprovisionamiento de electricidad. Entonces les pregunté que si de verdad era clandestina cómo era posible que lo supieran ellos, es decir, la autoridad, y me dijeron que siempre era mejor que hubiera una buena discoteca clandestina, ubicada y vigilada, donde la gente pudiera ir a desfogarse, incluidos los mandos, pues, según dijeron, el temperamento del colombiano era ése ${ }^{32}$ (Gamboa 2003: 29).

\footnotetext{
${ }^{31}$ R. Cánovas, "Juegos edénicos en Pantaleón y las visitadoras, de Mario Vargas Llosa. Una recapitulación", en Acta Literaria, 25 (2000), pp. 123-132. Internet. 23/05/04. <http://www.scielo.cl/scielo.php?script=sci_ arttext\&pid=S0717-68482000002500010\&lng=es\&nrm=iso\&tlng=es\#*>

${ }^{32}$ Como sucede en tantas obras de Vargas Llosa, los ataques contra el ejército y los militares están presentes en esta novela corta, no sólo por la permisividad con la existencia de un local clandestino, sino por el argumento mismo del relato: los paramilitares, la guerrilla el ejército e incluso los narcos se enfrentan en una lucha de todos contra todos, en la que el caos y la desorganización son evidentes. Y en mitad de ese horror acontece la historia protagonizada por Bryndis Kiljan y Olaf K. Terribile, dos corresponsales de guerra que investigan las razones por
} 
El realismo descarnado con que el narrador describe el ambiente, un realismo que roza casi lo expresionista y esperpéntico, no se aleja demasiado del estilo duro de los mejores narradores de novela negra, pese a no ser "El cerco de Bogotá" tal cosa. Y, por supuesto, actualiza otros prostíbulos malolientes de las letras hispanoamericanas ${ }^{33}$ :

Luego fue al baño y, junto a otras clientas sumamente alteradas, se metió cuatro rayas de coca. En uno de los reservados, una joven con los ojos en blanco y la piel llena de granos fumaba algo de olor dulce. Otra, sentada en el suelo, dormitaba contra el muro. De su brazo colgaba una jeringa llena de sangre. Más allá, en el último de los reservados, dos mujeres tocaban a otra con una botella, en un gesto que parecía tener algo de sexual. A Bryndis le llamó la atención, pero olía un poco a vómito y a excrementos, así que decidió volver a la sala (Gamboa 2003: 38).

Las referencias al mal olor, metáfora de la descomposición social, proliferan en Perder es cuestión de método, como antes vimos a propósito de ¿Quién mató a Palomino Molero?: "huele peor que pedo de borracho" (12), "olía a orines de gato" (39), "esto huele mal" (47), "huele a pedo de chigüiro" (47), "a mí este Tiflis me huele mal" (93), "podía soportar el espectáculo de la pobreza, pero no sus olores" (119), "un fuerte olor a limpión y a grasa fría les revolcó el estómago" (168), "un olor a tierra húmeda les llenó las fosas nasales” (169), "la cosa huele mal" (219).

Quizá una de las semejanzas más profundas entre ambos novelistas sea la de la concepción del fracaso. La crítica ha analizado la presencia de la derrota en las primeras novelas de Vargas Llosa ${ }^{34}$, y esa misma concepción de la existencia por parte de los personajes puede rastrearse en ¿Quién mató a Palomino Molero?, sobre todo en lo que concierne a los investigadores: la falta de reconocimiento público, la burla de Doña Adriana, el castigo del traslado o el desánimo que esas circunstancias conllevan conforman dicha sensación. La predilección de Gamboa por los perdularios no sólo tiene su origen en la obra de Graham Greene ${ }^{35}$, sino que también se relaciona con esta tendencia vargallosiana, hasta el punto de que elabora en Perder es cuestión de método toda una práctica literaria en la que explora el fracaso individual y colectivo en sus distintas modalidades.

Al margen de las coincidencias -voluntarias o no- entre las obras de corte policial de Santiago Gamboa y ¿Quién mató a Palomino Molero?, es evidente que Santiago Gamboa tiene modelos diversos para la construcción de sus tramas: conocedor de los orígenes de la novela policíaca clásica, se ha sentido más cercano a los clásicos del género negro (literario

las que la guerrilla ha acribillado un autobús lleno de armas que iba a ser vendido por miembros del ejército a los propios guerrilleros.

${ }^{33}$ Puede consultarse al respecto la obra de Rodrigo Cánovas, Sexualidad y cultura en la novela hispanoamericana. La alegoría del prostíbulo, Santiago de Chile, LOM Ediciones, 2003. El relato que comentamos no gira, como las novelas analizadas por Cánovas, en torno al burdel (El roto, 1920, del chileno Joaquín Edwards Bello; o Santa, 1903, del mexicano Federico Gamboa); sin embargo, el ambiente degenerado y corrupto de La Catedral nos transporta con facilidad a muchos de aquellos.

${ }^{34}$ M. E. Davis, "La elección del fracaso: Vargas Llosa y William Faulkner", en J. M. Oviedo (ed.), Mario Vargas Llosa, Madrid, Taurus, 1981, pp. 35-46.

${ }^{35}$ C. Quesada Gómez, "Perder es cuestión de método: una poética del fracaso", en Revista Crítica de Literatura Latinoamericana, 59, XXX (2004), Lima-Hanover (en prensa). 
y cinematográfico), a la vez que a otros escritores hispanoamericanos y españoles ${ }^{36}$. Además, el autor colombiano va mucho más lejos que Vargas Llosa en lo que respecta al alejamiento del género gracias a la parodia: no sólo introduce procedimientos antipoliciales, sino que recurre a lo que Linda Hutcheon denomina "estrategias retóricas de la parodia", como la ironía, el humor, la comicidad o la exageración. ${ }^{37}$ En este sentido, es posible colocar Perder es cuestión de método en una línea que parte del género policial pero que lo trasciende irónicamente.

\section{REFERENCIAS BIBLIOGRÁFICAS}

ARISTIZÁBAL, Luis H., "La generación de la diáspora contraataca", en Boletín Cultural y Bibliográfico, 45, XXXIV (1997). Biblioteca Virtual Banco de la República. Internet. 19/05/04.

$<\mathrm{http} / /$ www.banrep.gov.co/blaavirtual/boleti1/bol45/ resen.htm>

Armas Marcelo, J. J., Vargas Llosa. El vicio de escribir, Madrid, Alfaguara, 2002.

ANÓNIMO (nota de prensa), "Es muy atractivo armar desde lejos una patria imaginaria", entrevista para La Maga, 16 de diciembre de 1997. Internet. 12/05/03. $<\mathrm{http}: / /$ www.lamaga.com.ar/www/area2/pg_nota.asp?id_nota=3643>

CÁNOVAS, Rodrigo, "Juegos edénicos en Pantaleón y las visitadoras, de Mario Vargas Llosa. Una recapitulación", en Acta Literaria, 25 (2000), pp. 123-132. Internet. 23/05/04. <http://www.scielo.cl/scielo.php?script=sci_arttext\&pid=S07176848200000 2500010\&lng=es\&nrm=iso\&tlng=es\#*>

CÁNOVAS, Rodrigo, Sexualidad y cultura en la novela hispanoamericana. La alegoría del prostíbulo, Santiago de Chile, LOM Ediciones, 2003.

Colmeiro, José F., La novela policiaca española: teoría e historia crítica, Barcelona, Anthropos, 1994.

DAVIS, Mary E., "La elección del fracaso: Vargas Llosa y William Faulkner”, en Oviedo, José Miguel (ed.), Mario Vargas Llosa, Madrid, Taurus, 1981, pp. 35-46.

ESTABLIER PÉREZ, Helena, Mario Vargas Llosa y el nuevo arte de hacer novelas, Alicante, Universidad de Alicante, 1998.

GamboA, Santiago, Perder es cuestión de método, Barcelona, Mondadori, 1997.

GAMBOA, Santiago, El cerco de Bogotá, Barcelona, Ediciones B, 2003.

GAMBOA, Santiago, "Literatura y prensa en Colombia" (inédito). Existe una traducción publicada: "Secret Histories. On the creation of a Colombian national identity

\footnotetext{
${ }^{36}$ Como muestra del buen conocimiento que Santiago Gamboa posee del género, puede verse el texto "Literatura y prensa en Colombia", que no ha sido publicado en español, pero sí en inglés: "Secret Histories. On the creation of a Colombian national identity through crime fiction" (trad. de Rafael Reyes-Ruiz), Boston Review (summer 2001). Internet. 22/05/04. <http://www.bostonreview.net/BR26.3/gamboa.html $>$ Agradezco al autor que me haya facilitado el texto original inédito.

${ }^{37}$ L. Hutcheon, A Theory of Parody: the Teachings of Twentieth-Century Art Forms, New York / London, Methuen, 1985.
} 
through crime fiction" (trad. de Rafael Reyes-Ruiz), Boston Review (summer 2001). Internet. 22/05/04. <http://www.bostonreview.net/BR26.3/gamboa.html>

GIARDINELLI, Mempo, El género negro. Ensayos sobre literatura policial, México D. F., Universidad Autónoma Metropolitana, 1996.

HeRnández DE LÓPEZ, Ana María, "Que el racismo mató a Palomino Molero no es la verdad de las mentiras", en Mario Vargas Llosa: opera omnia, Madrid, Pliegos, 1994, pp. 125-132.

Hutcheon, Linda, A Theory of Parody: the Teachings of Twentieth-Century Art Forms, New York / London, Methuen, 1985.

OrTEGA, Julio, “García Márquez y Vargas Llosa, imitados”, en Revista Iberoamericana, LII, 137 (1986), pp. 971-979.

PÖPPEL, Hubert, La novela policíaca en Colombia, Medellín, Editorial Universidad de Antioquia, 2001.

QuesADA GóMEZ, Catalina, "Páginas de urgencia”, en Quimera, 244 (mayo 2004), pp. 7476.

QueSADA GÓMEZ, Catalina, "Perder es cuestión de método: una poética del fracaso", en Revista Crítica de Literatura Latinoamericana, 59, XXX (2004), Lima-Hanover (en prensa).

RYAN-RANSON, Helen L., "Lo grotesco en ¿Quién mató a Palomino Molero?", en Hernández de López, Ana María (ed.), Mario Vargas Llosa: opera omnia, Madrid, Pliegos, 1994, pp. 139-150.

SKLODOWSKA, Elzbieta, La parodia en la nueva novela hispanoamericana (1960-1985), Amsterdam / Philadelphia, John Benjamins Publishing Company, 1991.

TAGgart, Kenneth M., "La técnica del contrapunto en ¿Quién mató a Palomino Molero?”, en Hernández de López, Ana María (ed.), Mario Vargas Llosa: opera omnia, Madrid, Pliegos, 1994, pp. 151-158.

TANI, Stefano, The Doomed Detective: The Contribution of the Detective Novel to Postmodern American and Italian Fiction, Carbondale, Southern Illinois Up, 1984.

TODOROv, Tzvetan, "Typologie du roman policier", Poétique de la prose, Paris, Éditions du Seuil, 1978, pp. 55-65.

VArgas Llosa, Mario, ¿Quién mató a Palomino Molero?, Barcelona, Seix Barral, 1986.

VÁZQUEZ DE PARGA, Salvador, La novela policiaca en España, Barcelona, Ronsel, 1993. 